cardiac sounds were heard with difficulty but seemed to be clear at the apex; no adventitious sounds could be detected in this situation. Nothing abnormal was discovered on examination of the lungs. There was no pyrexia.

The patient was put to bed immediately and was kept absolutely quiet in the recumbent position, the head being fixed in position by means of sand-bags, and no pillow Hllowed. Here I should add that the patient greatly assisted by lying perfectly still. The diet was restricted as far as possible, both as regards fluids and solids, but the strict régime was not forced and at the end of the first week he was allowed an ordinary fisb diet, all stimulants being withheld. Iodide of potassium was administered internally in doses of ten grains three times a day, the dose being quickly and steadily increased so that by the end of the third week 60 grains were being taken three times a day, with no ill-effects at any time. As a local application to the swelling collodion was painted all over its surface every night and morning.

I expected a rapid anc steady downward progress towards a fatal issue and to hear at any time that the aneurysm had ruptured externally, but bappily my anticipation was not fulfilled and the patient began to improve from almost the commencement of the treatment. As soon as he was fully under the influence of the iodide of potassium the pain was greatly relieved and later practically disappeared. At the end of ten days the size of the aneurysm appeared to be diminished and the pulsation less marked, the walls seemingly becoming thicker, showing that clotting was taking place witbin the sac; the dusky swelling was also lessening in size. The imorovement, continued and at the end of three werks the patient stited that he had not felt so well for the la-t four years. More liberal diet was now allowed. He was still, however, kept in the recumbent position, the collodion was applied night and morning, and

FIG. 2.

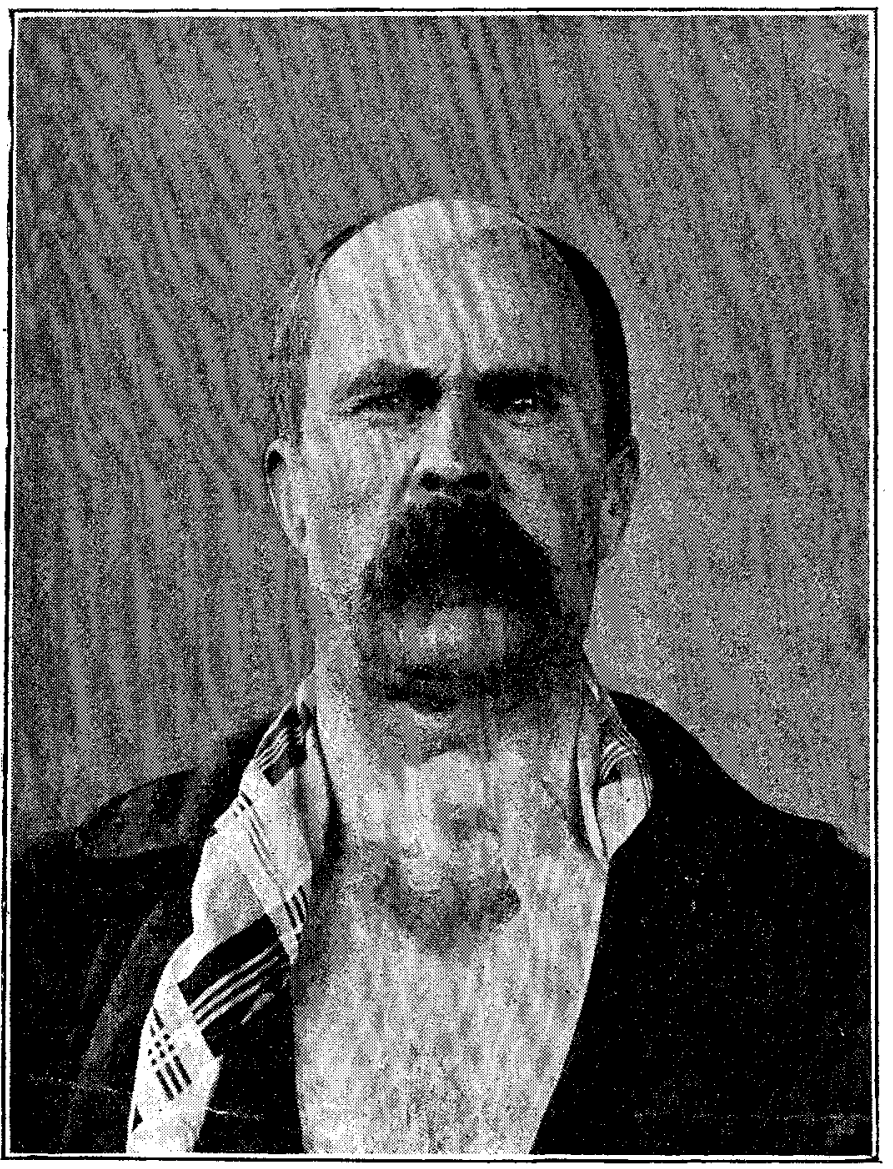

Appearance of the patient at the date of his discharge from the lospital.

the potassium iodide was continued. At this time the swelling was steadily decreasing in size and the walls were becoming firmer. Towards the end of the sixth week he was allowed to sit up in bed but was still kept quiet; a full meat diet was permitted with no restrictions, except as regards stimulants. On July 22nd the patient was allowed to leave his bed for the couch with no unsatisfactory result. From that day more and more liberty was granted, the same medicinal treatment being continued, and in the ninth week he became a most useful convalescent patient in assisting in the work of the ward.

On August 22nd, the day before leaving the hospital to recommence his work, the patient's condition was as follows. The tumour was now much smaller, there was scarcely any visible expansile pulsation, the whole surface of the swelling was smooth, the protuberance having completely disappeared, and the overlying skin was everywhere normal (Fig. 2) (the dark patches in the picture being largely due to the collodion). The walls were very firm, thick, and well defined, and the impulse was considerably less marked. The measurements now were: circumference of the neck at the most prominent part of the swelling, 17 inches; greatest length of the swelling in a vertical direction, 4 inches; greatest breadth, 4.4 inches. The cough had entirely disappeared and the patient had increased in weight; the voice was, however, still somewhat harsh.

I have to thank Dr. Wheelton Hind most cordially for his kindness in allowing me to use the notes.

Stoke-on-Trent.

\section{CONCUSSION OF THE SPINE, WITH SOME REMARKS ON CONCUSSION IN} GENERAL.

BY EDRED M. CORNER, B.Sc. LOND., M.A., M.B., B.C. CantaB., F.K C.S. Eng.,

SURGEON TO OUT-PATIENTS AT ST. THOMAS'S HOSPITAL; SENIOR ASSISTANT SURGEON TO THE CHILDREN'S FOSPITAL, GREAT ORMOND-STREET.

Concussion of the spine is a subject about which there has been a great deal of misunderstanding. This has in part arisen on account of the phrase having been used, both popularly and professionally, in connexion with railway injuries. Mr. H. W. Page, as the result of his vast experi. ence of these cases, says : "It is not intended to bring forward the evidence, which is conclusive and can be found elsewhere, as to the absence of intraspinal injury in the vast majority of cases where there is complaint of spinal pain. It must suffice to remind the reader of the fact that the physical relations of the spinal cord and the bony canal in which it lies are wholly different from these of the brain and skull, and that they do unquestionably protect the cord from the injurious effects of blows on the back, such as, were they to fall on the head they would be likely to cause concussion of the brain. It may, indeed, be said at once that concussion of the spine is one of the rarest of injuries, and that, as the writer has shown in another place, railway collisions are not especially prone to provide examples of it. 'Concussion of the spine' and 'railway spine' are therefore bad and misleading terms to employ in speaking of the kind of spinal injury which is common in railway accidents ; and they are still worse to apply to the general effects on the nervous system ${ }^{2}$ when there is no accompanying injury to the back. The height of absurdity is reached when either the one term or the other is used for a functional neurosis in which there is nothing wrong with the spine, and the person suffering has never been in a railway accident." The above was written in 1893. In $1900 \mathrm{Mr}$. C. H. Golding-Bird and Mr. G. Bellingham Smith wrote as follows: "The question of spinal concussion is a vexed one. While some surgeons practically deny its existence others class under that name conditions that are now known to bear a different interpretation. As in past years many paraplegic states were regarded as functional which we now with improved methods of investigation know to be the result of definite spinal lesions, so the generic term concussion is gradually becoming more and more limited in its application. By 'concussion of the spine' is meant a more or less complete annibilation of the functions of the cord, immediately consequent upon an injury, temporary in character, and unattended by any discoverable lesion." A consideration of these two authorities will show that the work of purification, begun years ago hy Mr. Page, has led to the gradual definition of the lesion, and it is hoped that the cases to be brought forward will lead to

These cases are examples of traumatic neurasthenia See paper in the International Clinics for 1906. 
its being recognised clinically. Before proceeding to the clinical side something must be said about the pathological changes presented.

When considered with regard to an organ, concussion may be separated at least into two kinds, general and local. There is naturally no line of distinction to be drawn between them. The differences are in the distribution and extent of the injury, not in its pathological character.

General concussion.-Shaking due to violence applied relatively at a distance from the part affected. By the term "relatively" is meant that the force is applied at such a distance that the resulting shaking is more or less uniform and equable in the organ under consideration.

Local concussion. - In this variety the violence is applied close to the organ in which the resulting shaking is not uniform or equable, being greatest near the site of the injury.

The pathology of concussion.-In the pathological explanation of concussion three chief views hold the field: that of molecular disturbance and displacement, that of multiple small bæmorrhages, and that of the displacement of the cerebro-spinal fluid (Duret). Of the last of these we need not speak, as there is little or no possibility of its being fficacious except in the brain. It is the first of these which forms the basis of the patbology of concussion. The essential for its production is a shaking of the part affected, causing some displacement of the constituent molecules in relation to one another. In slight shakings there is no visible or gross anatomical lesion. But if the shaking is more violent there may be minute anatomical lacerations produced by the movements of the molecules upon one mother, and so, multiple hæmorrhages. By means of variations in the severity of the shaking, and consequently in the magnitude of the lesions which result, all the clinical differences found in cases of concussion can be explained.

The brain may be said to consist of white and grey matter, the former of which is made up of medullated nerve fibres and the latter of non-medullated fibres and nerve cells. In concussion of the brain both of these structures are subjected to the shaking; but, according to their powers of resistance, they will be affected differently. There seems to be no apparent reason why the medullated nerve fibres in the brain and spinal cord should be more affected than those in the nerve trunks, such as the sciatic. The question of general concussion has never been raised in connexion with a nerve trunk, as distinguished from the results of a direct blow to a nerve which is an example of local concussion. In fact, although the injuries of nerves have been studied by some of the ablest of men the symptoms of no clinical case have been attributed to a general concussion of the nerve trunk. As the symptoms of general concussion of a medullated nerve have not been described it may be presumed that the symptoms of concussion of the brain are produced by the molecular disturbances in the grey matter and not in the white.

The situation where the non-medullated nerves fibres are most frequent is the sympathetis system. Of concussion of the sympathetic itself there is next to nothing known. But it is well known that concussion of the chest and abdomen gives rise to conditions of far more seriousness than do the like injuries applied elsewhere. Mr. A. Pearce Gould says : "In certain cases of severe contusion of the chest in which death supervenes instantaneously, or after a very short interval, no gross lesion is found to explain this result. In other cases more or less severe symptoms persist for hours, or even a day, but the most careful physical examination of the chest fails to reveal any lesion to account for them, or the symptoms cannot be explained by the lesions present." . $\mathrm{He}$ suggests three or four causes-stimulation of the intrathoracic branches of the vagus nerve, concussion of the heart, paralysis of the sympathetic, or anæmia of the brain. From what has been said in the earlier part of this paper it will be suggested that severe shaking of the non-medullated thoracic sympathetic will in concussion of the chest lead temporarily to its paralysis and the accumulation of blood io the mesenteric and other abdominal vessels. It would seem that concussion will affect the non-medullated sympathetic nerves and gánglia long before it is severe enough to stimulate the medullated fibres of the vagus. Concursion if the heart is concussion of its ganglia which are unprotected by any medulla, which will be affected similarly. laralysis of the sympathetic will leave the tonic inhibitory

2 Treves's System of Surgery, vol. ii, p. 401 action of the vagus on the heart without an antagonist and will produce symptoms like vagus stimulation.

In concussion of the chest there must be some lesion of the sympathetic system ; such lesion must be of the nature of general concussion rather than that of a direct blow. So that on the meagre evidence which is at present available there is reason to believe that there is such a thing as clinical concussion of a non-medullated nerve fibre or ganglion and not of a medullated nerve fibre-tbat is to say, of grey matter and not of white. This is wbat one would expect. The inclosing of a nerve fibre, or better, of an axis cylinder, by a fatty envelope, whatever its other functions may be, must serve to protect that fibre from external violence or injury. Such an investment must be a necessary accompaniment of the evolution of practically every animal. The daily life of every animal, from the most primitive to the most complex, especially when endowed with the power of movement, must entail a number of concussions or shakings. Pari passu with the bigher and more complex development of the nerve centres goes a greater vulnerability to injury, and also, usually, an increased danger of concussion. Hence a still greater need of the protection of the nerve structures. The very protection of these parts is an absolutely necessary act-that is to say, a postulate or axiom for the fitting of an individual for the struggle for existence. We can then form some idea of one cause at least in the evolution of the medulla of the sheaths of nerves. About the medullation of nerve fibres in the animal series but little is known, except that it is not found in the Jowest forms, while medullation is universal in the higher. Even in them at birth, for instance, the white rat has no trace of medullation in its nervous system at that date. Dr. Watson of Chicago $^{3}$ found that the rate of medullation did not keep pace with the development of psychic activities and associations. Moreover, the anatomical situations of the early appearances of medullation are not readily understood. In the human subject more and more nerve fibres become medullated as life progresses. ${ }^{4}$

In connexion with the view that the medulla of a nerve has a protective function for its axis-cylinder may be mentioned two facts-namely, the somatic nerves-are those from their distribution most liable to injury and are medullated, whilst the visceral or splanchnic nerves are non-medullated; and the non-medullated grey matter of the spinal cord is internal and surrounded by a protective layer of white medullated matter. In both cases there is a suggested confirmation of the view put forward that white matter is protected and therefore protective to the grey. In the brain the disposition of the grey and white matter is the opposite; the former is on the surface forming the cortex, as well as within forming the so-called basal ganglia, nerve nuclei, \&c. The question of this disposition is wrapped ap with that of the development of the cortex cerebri and is beyond our knowledge at present.

To resume the discussion of concussion of the brain it must be pointed out that the grey matter consists of both non-medullated axis-cylinders and nerve cells. Considering the far greater gravity of the symptoms in concussion of the brain than in concussion of the chest it may be concluded that the most severe lesion in the former is to the nerve cells themselves, a circumstance which we should naturally expect from their greater complexity and specialisation. It would seem that the medullated nerves, the non.medullated nerves, and the nerve centres or cells form a series of increasing intensity of reaction to the violence of shaking. We are quite accustomed to the concussions of our daily existence and are not inconvenienced by them. But if we are placed in a position and exposed to shakings to which we are not nervously adapted then we suffer the discomforts (to many people) of sea and railway travel.

Having thus differentiated between the effects of concussion on the constituent structures of the nervous system in general we will now pass on to the consideration of the same condition in the spinal cord in particular. To begin with, the surroundings are perfectly different in the two cases. For instance, the brain is anchored by the nerves at its base, whilst its upper part can make considerable excursions. In the case of the spinal cord it is different. The cord is tethered on both sides by the nerves and the ligamentum denticulatum, so that it cannot come into contact with the walls of the canal in which it lies. Thus 
there have been ro lesions of the spinal cord attributed to contrecoup, as is the case with the brain. We must therefore agree with Mr. Page that concussion of the spine must be one of the rarest of injuries. But I believe it can be recognised clinically and should like to direct attention to a condition which has not been recognised as being due to concussion of the spine. If this is correct then local, as distinguished from general, concussion of the spine is by no means so infrequent as many authorities would lead us to expect.

OASE 1. Local conoussion of the spine; fracture of the axis. (Shown before the Clinical Society of London, October, 1903..$^{5}$ - A man of about 45 years of age was returning home on horse-back. Being very tired he was half asleep, so that when his horse quietly subsided on to its knees he slid down its neck and alighted on his head. Then the horse ran away, leaving him on the ground. There was never any loss of consciousness ; indeed, his mind was preternaturally clear. He was paralysed in all four limbs, with corresponding anæsthesia. He lay on the ground for about 20 minutes, when someone came up to him and remarked upon the curious crossed position of his legs, of which he was quite unconscious and powerless to rectify. He was given brandy, shortly after the administration of which the paralysis and anæsthesia began to pass off. The total duration of these symptoms was about half an hour. He was very ill for some weeks, not daring to sleep for fear his head should drop. Suffice it to say, that it was only after the lapse of six years that the existence of a fracture of his second vertebra, the axis, was proved to have occurred by means of the $x$ rays.

As this case was not seen at the time of the accident the story was received with some caution. But when a second man came with a similar history it was realised that these cases might represent concussion of the spine. For a long time it had been recognised that the vertebræ could contuse the cord and spring back so that no lesion of the column was apparent, yet concussion had not been recognised in this connexion.

CASE 2. Local conoussion of the spine; fracture of the fifth cervival vertebra. (Shown before the Clinical Society of London, 1904 and $1905^{6}$ ) -A man, about 20 years of age, by profession an acrobat, in the performance of his part received an injury to his neck which was followed by an immediate paralysis and anæsthesia of all four limbs and the trunk. As in the former case the symptoms cleared up in about 20 minutes, the clearance rapidly following the administration of brandy, go that it would appear that the stimulation of the circulation had something to do with it. The man subsequently recovered completely and a skiagraph showed that he had a fracture of the body and the pedicles of his fifth cervical vertebra.

The above two cases represent a local or segmental concussion rather than a generally distributed lesion through the spinal cord. It was probably produced by a blow from the vertebræ which sprang back into positions in which the cord was safe.

General concussion of the spine must be a very rare thing and still rarer must it be for it to be recognised clinically. As has been seen, the spinal cord is excellently protected and a shaking sufficiently violent to cause general concussion of the spinal cord will at the same time produce such violent concussion of the brain and perbaps of the sympathetic system that all symptoms referable to the spinal cord will be completely masked.

Marginal concussion of the spine.-There is a third class of case in which we may look for signs of spinal concussion as defined above in the two illustrative instances. Whenever there has been a serious lesion to the cord, the segments immediately above and below the seat of that injury will be concussed. This marginal concussion will of necessity be frequently masked by the pressure of a hæmorrhage. It is therefore beholden upon us to be on the look out for its occurrence. It is quite possible to recognise the concussion which accompavies, and is above, a gross spinal injury, always provided it is not obscured by a hæmorrhage-that is to say, concussion of the segment of the cord at the margin of the injury can be recognised clinically. Three cases will be quoted to exemplify tbis.

CASE 3. Fracture-dislocation of the spine; marginal concussion. ${ }^{8}$ - The patient, a male, aged 31 years, fell from the

5 Transactions of the Clinical Society of London, 1906. is Ibid.

$$
7 \text { Ibid., 1903, p. } 234 .
$$

8 St. Thomas's Hospital Reports, 1899, p. 193. third storey of a house to the ground. On admission to St. Thomas's Hospital, amongst other signs, anæsthesia extended op to the third dorsal nerre. By the next day, feeling had returned almost as far as the umbilicns-that is, the region supplied by the tenth dorsal nerve. Post mortem there was a fracture-dislocation of the seventh dorsal vertebra with transverse rupture of the cord.

CASE 4. Dislooation of the spine; marginal conoussion. ${ }^{9}-$ The patient, a man, aged 22 years, had fallen from a railway trolley and bad hurt his neck. On admission to hospital amongst other signs there was total anæsthesia up to the level of the second dorfal nerve. In one and a half hours the anæsthesia had cleared up as far as the nipple. Post mortem the fifth cervical vertebra was dislocated forwards on the sixth ; there was some very slight bæmorrbage at the seat of the injury.

CASE 5. Dislosation of the spine; marginal annoussion. ${ }^{10}$ The patient, a man, aged 21 years, injured his neck at sea. Two minutes after the accident there was "paralysis of all sensory and motor nerves of all four limbs and of the trunk up to the nipples." 'Three hours after the accident he had recovered the use of his arms, except in those muscles supplied by the ulnar nerves. A skiagraph showed a disloca. tion of the sixth cervical vertebra.

The three selected cases just given illustrate the condition which $I$ have urged is a true concussion of the spinal cord beyond the limit or margin of the gross injury. In Cases 3 and 4 the clinical recognition was made by the area of ar æsthesia clearing up very quickly in such a way as to be inexplicable upon the generally accepted view of spinal hæmorrbages. Case 5 illustrated a similar clearing up of motor symptoms. In these three cases brief mention of such points has been made as was necessary to exemplify and not. to obscure the clinical recognition of marginal concussion of the spinal cord. It is suggested that at the moment, or shortly after an injury to the spine, the motor and sensory symptoms exceeded the area indicated by the injury. If this excess of symptoms is due to concussion of the cord and is not obscured-i.e., perpetuated, increased, or decreased by a bæmorrbage--it will clear up or begin to clear up in a few hours. Later excess of signs and symptoms is due to bæmorrhages. Still later, after the third day, it will be due to inflammation, myelitis.

The following case is recorded as the best fatal example of a local or segmental concussion of the spine which has passed under my notice.

CASE 6.-A man, aged 73 years, was found unconscious lying on the floor of a stable, having been kicked between the shoulders by a horse. He was semi-conscious but could affirm the history of the kick. On examination there wer: a bruise bigh up between the shoulders and complete paralysis and anæsthesia of the lower limbs and lower part of the trunk. Breathing was almost entirely diaphragmatic and the movements of the upper limbs were limited to flexion of the wrists and the fingers. Anæsthesia, priapism, and retention of urine were present. The pulse was 44 and the temperature was normal. Death took place on the second day. Post mortem there was no fracture or dislocation of the spinal column. There was no visceral disease. The cord itself showed no sign of hæmorrhage within or without, but appeared much softened, "probably due to postmortem changes." There was no obvious cause for death.

Owing to the mental and grave bodily condition of the man the clinical examinations were very incomplete. Hence there is no idea of the clinical recognition of spinal concussion in this case. In fact, it is merely recorded as an example of a fatal case, showing symptoms of paralysis and anæsthesia, for which there were no obvious causes to be found in the vertebral column, spinal cord, or its membranes. The case may therefore be regarded as an example of the pathological recognition of a spinal concussion.

It is hoped that the discussions in this paper will bave done something towards clearing our ideas on a subject which is hazy and obscure with the traditions of the past. Concussion of the spine has been subdivided into general and local concussions : the former we can hardly hope to recognise during life, and not at all after death; the latter we can recognise during life as segmental concussion of the cord, and can infer its presence after deatb. We can recognise it : lso in the excess of signs and symptoms abore a gross spinal ivjury, marginal concussion, provided they are not obscured by a hæmorrhage. Pathologically, it has been

9 I bid., 190', p. 190.
10 Ibid, 1900 , p. 189. 
suggested that the medulla of a medullated nerve fibre has besin developed during evolution, in part, to protect the axiscylinder from the concussions of the daily life of an organism.

Harley-street, W.

\section{A NOTE ON BORIC ACID RELATIVE TO APPENDICITIS.}

BI REGINALD HARRISON, F.R.C.S. ENG.,

PAST FICE-PRESIDENT AND HUNTERIAN PROFESSOR OF PATHOLOGY AND SURGERY, ROYAL COLLEGE OF SURGEONS OF FNGLAND.

Ir has been stated with some authority that the frequency of appendicitis has been considerably added to in recent years by the large use of boric acid and other chemicals as food preservatives. Though such a suggested connexion does not at first sight appear obvious, it seems to be a subject worth further consideration.

Some years ago I was making observations on the action of boric acid (as well as other drugs) administered internally with the object of sterilising the urine in connexion more especially with the prevention of urinary fever following operations on the urinary oryans. I also extended these observations in another direction-namely, to that suggested by Rainey's work on Molecular Cualescence relating to the artificial production of urinary gravel and calculi.

In THE LANCET of March 14th, 1903, at p. 749, an annotation appeared on the disturbing effects of boric acid on the digestion of healthy persons and invalids when taken internally. I ventured to endorse this statement, in consequence of seeing many persons suffering from these effects, in a letter which appeared in THE LANCET of the following week (p 836). The prominent symptom complained of was dyspepsia accompanied by very great and distressing Hitulency. Accordingly, as st ated in my letter, I abandoned horic acid for the purpose mentioned and used boracite which I have continued to find an excellent and unimpeachable substitute.

After enumerating a number of food preservatives, of which boric acid was a frequent one, Lr. Kichard Jones, in his address ${ }^{1}$ to the North Wales branch of the British Medical Association, observes that "there can be no doubt that the continuous introduction of these chemical substances into the system interferes with digestion, depresse: the heart action, and injuriously affects the kidney," and further he points out that the rate of deaths during 1885-1904 from enteritis, appendicitis, and perityphlitis has increased from 133 to 305 per million.

In his treatise on appendicitis $\mathrm{Dr}$ Dearer of Philadelphia, C.S.A., states: " $O$ ef the exciting causes of appendicitis from the clinical point of view disturbances of digestion are the most important. Such is the prominence of these in the etiology of appendicitis and with such constancy have they been observed that it is unhesitatingly asserted that appropriate inquiry will elicit a history of such disturbances in almost all cases."

Ir has always seemed reasonable to me to infer from my surgical dealings with this affection that some mechanical condition, insufficiently explained, connected with the function of digestion would eventually be determined as playing an important part in its causation.

It may be assumed that the appendix takes no part in the digestive or intestinal function and is not structurally or physiologically fitted for it; in fact, it would appear that any attempts to use it as a receptacle for titber the natural or accidental contents of the canal may be the first step in the process which eventually ends in inflammation of this blind and rudimentary sac. Anything entering it, gaseous or otherwise, must be incapable of "moving on," and unless regurgitation haply and fortunately takes place the imprisoned contents are likely to undergo antive bacterial decomposition with the evolution of foul and irritating gas.

The initial lesion which probably renders appendicitis possible is the opening or blowing out of the appendical canal to such a degree as to render it accessible to the contents of the intestines as carried along by the ordinary and estraordirary means of propulsion technically known as peristaltic action. When this condition has thus been fairly well established the ease and even life of the appendix, not to say anything of the individual, are liable to become precarious. In this sense flatulent dyspepsia, however produced, may lead up to an appendicitis.

Under the title of "Traumatism as an Etiological Factor in Appendicitis," Dr. W. J. McDonald has recorded some interesting cases ${ }^{2}$ where appendicitis has apparently followed injuries in which the abdomen has been suddenly and violently compressed. Surely the primary lesion in these instances was the opening up of the appendical canal and subsequent access to it by the intestinal contents. The compression sufficiently exercised by an inverted bag containing more or less gas must almost necessarily discover any weak or patent spot in its wall, just as emphysematous air confined in other parts of the body. will show the line where least resistance is offered to the advance of extravasation of urine. Or, to take another example, an intestinal hernia may be either gradually or suddenly formed. So in like manner may an appendix be prepared beforehand to receive and detain whatever the bowels contain, though the latter events need not necessarily bappen. In these days when Acts of Parliaments and persu usive advertisers seem to regulate what we may or may not put into our stomachs a careful scrutiny should be exercised as to what all this means.

Lower Berkeley-street, W.

\section{A CASE OF OSTEITIS DEFORMANS WITH HUNTINGTON'S CHOREA.}

\section{BY CHARLES MACKEY, M.B. VICT,}

ASSISTANT MEDICAI, OFFICER TO THF COLTIY ASYLLA, LANCASTER.

A MAX, aged 57 years, a labourer, was admitted to the County Asylum, Lancaster, on Feb. 2ad, 1904. 26 years ago the patient was said to have sustained a "severe injury to the spine." He began to suffer from "twitchings" 12 years ago and for some time had bad pains in his back. It was difficult to say definitely whether he had had syphilis or not, but there were several old scars in the right inguinal region. With regard to his family history, the patient was married and had had eight children, five of whom were healthy; the remaining three "died in infancy." His father died from "paralysis" and the patient's uncle was said to have had chorea. The patient was fairly well nourished and showed deformities of the limbs and trunk (see fizure), mental disorder, and irregular, involuntary, spasmodic movements of the limbs, the trunk, the neck, and the face. All his teeth were sound and very well preserved. The circulatory system was normal. As to the respiratory system, there was want of resonance over the right-apex and here the breath sounds were hareh in quality. Sonorous rhonchi were audible over scattered areas of the left lung. The patient's mental state was as follows. He was emotional and simple in conversation and behaviour. His memor 7 for recent events was impaired. His intellectual faculties were b'unted, being unable to hold a conversation or answer any but the simplest questions. When druys were withbeld he slept in a fitful manner, just appearing to doze for from ten minutes to half an hour at a time. During the day there was marked restlessness. His speech was slurred and explosive in character, with recurring utterances. Muscular power appeared to be normal but there was some wasting in the following muscles on each side: the biceps, the triceps, the supraspinatus, the infraspinatus, the pecto. ralis major, and the deltoid. There was well pronounced muscular incoördination of the limbs, the lower jaw, and the tongue. This incoördination was very evident when the patient attempted to take anything out of his pocket, as he then had to make several trials even to get a hand inside the pocket, and it was also noticeable when he was told to open his mouth or put out his tongue. Fine fibrillary twitchings were seen in many of the muscles of the trunk, the neck, the face, and the limbs. There were also marked choreiform movements of these parts and such spasms were intensified by emotion and ceased during sleep. In walking the patient swayed his whole body from one side to the other, taking very short steps and sliding his feet along the ground. He had a limp owing to the difference in the 